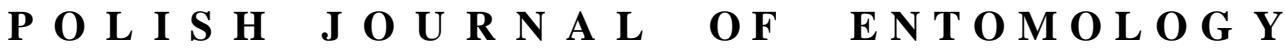

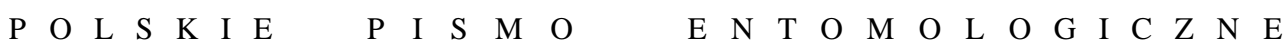

VOL. 86: 91-97

Lublin

31 March 2017

DOI: $10.1515 /$ pjen-2017-0007

\section{First record of Phytodietus moragai GAULD, 1997 (Hymenoptera: Ichneumonidae: Tryphoninae) from Ecuador, with a description of the female of this species}

\author{
AgAtA Kostro-AmbroZIAK $^{1 *}$, FiLIPPO Di GiOvAnNI ${ }^{2}$ \\ ${ }^{1}$ Department of Invertebrate Zoology, Institute of Biology, University of Bialystok, \\ Ciołkowskiego 1J, 15-245 Białystok, Poland \\ ${ }^{2}$ Università di Roma "Sapienza", Dipartimento di Biologia e Biotecnologie \\ "Charles Darwin”, Sede di Entomologia - Piazzale Valerio Massimo 6, \\ I-00185, Rome, Italy
}

\begin{abstract}
Phytodietus moragai GAULD, 1997, previously known from Costa Rica, is recorded from Ecuador for the first time. This is the second representative of the genus Phytodietus Gravenhorst, 1829 from South America. A description and illustration of the female of $P$. moragai is provided.

KEY WORDS: Ichneumonid, Neotropical region, South America, P. cooperi, Costa Rica, taxonomy.
\end{abstract}

\section{INTRODUCTION}

The worldwide distributed genus Phytodietus GRAVENHORST, 1829, belonging to the subfamily Tryphoninae of Ichneumonidae (Hymenoptera), includes 122 described species (BENNETT 2015, KASPARYAN \& KHALAim 2013, Kostro-AmbroziaK 2011a, 2011b, 2012, KOSTRO-AMBroziAK \& BROAD 2016). To date, 22 species of this genus have been recorded in the Neotropical region, 21 of which are known from Mesoamerica (Mexico,

*Corresponding author: ambro@uwb.edu.pl 
Costa Rica) (GAuld et al. 1997, Kasparyan 2007, Kasparyan \& Khalaim 2013, KASPARYAN \& RUíz-CANCINO 2004, KHALAIM et al. 2013) but just one, P. cooperi, from South America (Ecuador) (KOSTRO-AMBROZIAK \& BROAD 2016).

During a survey of parasitoid insects carried out by Dr INCLÁN around Calacali in the northern highlands of Ecuador, a female of Phytodietus moragai GAULD, 1997 was found. The species was originally described from Costa Rica based on two males (GAULD et al. 1997). Hitherto, only one additional male of this species has been recorded, also in Costa Rica (CORONADO-RIVERA 2009). Here P. moragai is recorded as new to Ecuador and a description of the female of this species is provided. This is the second record of the genus Phytodietus from South America.

\section{MATERIAL AND METHODS}

The female of P. moragai is preserved in the collection of the Laboratory of Ecology and Evolutionary Biology of Insects, University of Białystok, Poland (LEEBI). The photographs were taken using an opto-digital microscope DSX110. The morphological terminology follows GAULD et al. (1997).

\section{TAXONOMY}

\section{Phytodietus moragai GAULD, 1997}

(Figs 1-9)

\section{Comparative diagnosis}

P. moragai can be easily distinguished from $P$. cooperi KosTRO-AMBROZIAK \& BROAD, 2016, the second Ecuadorian species of the genus, by the following features: occipital carina complete (ventrally incomplete in P. cooperi); metasoma predominantly orange (predominantly black in $P$. cooperi); wings hyaline (entirely brownish infumate in $P$. cooperi).

\section{Material examined}

[ECUADOR - Calacali, 11-24.XI.2014, D. J. INCLÁN leg., Malaise trap], [Phytodietus moragai GAULD, 1997, + , det. A. Kostro-AmbroziaK] - ( + , LEEBI). [Holotype], [COSTA RICA: San José Prov., San Antonio de Escazú, 1300 m, ix-xi.1987/8 (EBERHARD \& GAULD)], [Phytodietus moragai, det. I. D. GAULD, 1997] - (ð̂, BNHM). [Paratype], [COSTA RICA: Sn José Prov., San Antonio Escazú, 1300 m, XI. Gauld], [Phytodietus moragai, det. I. D. GAULD, 1997] - (§̂, BNHM). 


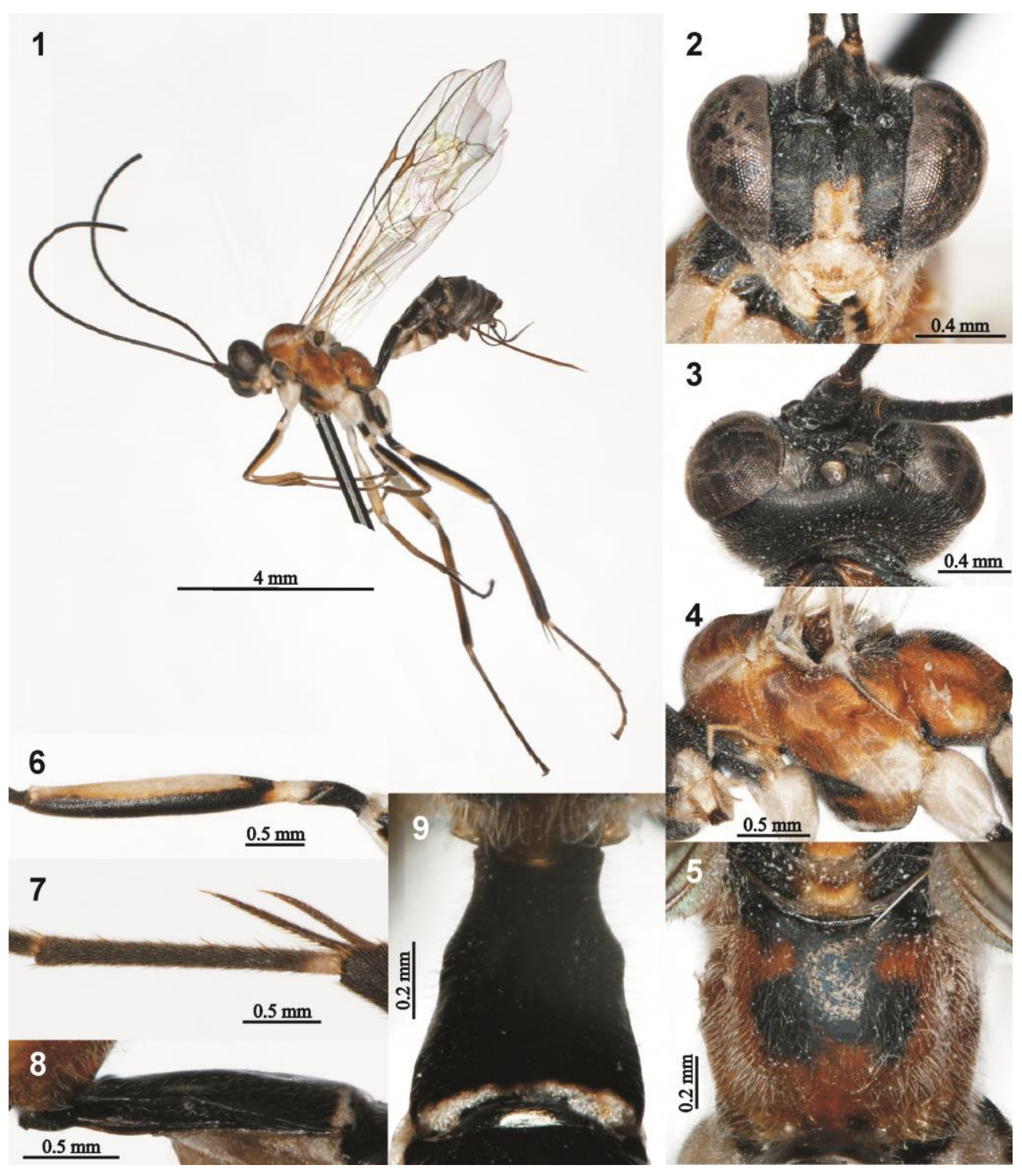

Figures 1-9. Phytodietus moragai, female: 1. habitus, lateral view; 2 . head, facial view; 3. head, dorsoposterior view; 4. mesosoma, lateral view; 5 . propodeum, dorsal view; 6 . hind femur, lateral view; 7. tibial spurs and first tarsomere of hind leg; 8. first metasomal segment, lateral view; 9. first metasomal segment, dorsoposterior view. 
Description. Female (Fig. 1). Body length $7.0 \mathrm{~mm}$.

Head. Face (Fig. 2) 0.88 times as long as wide, matt, covered with distinct leather-like structure and very weak punctures. Clypeus with transverse convexity visible mainly on sides, basally convex, apically inclined. Apical half of clypeus rather trapezoidal but with finely rounded margins, without visible notch centrally. Upper tooth of mandible only slightly longer than lower tooth. Malar space 0.76 times as long as basal width of mandible. Occipital carina distinct and complete, joining hypostomal carina before base of mandible. Temple behind eye (Fig. 3) narrowed but finely curved. Antenna with 37 flagellomeres; flagellomeres 1 to 4 unspecialized, not broader than distal ones.

Mesosoma (Fig. 4). In general subpolished to polished, with short but relatively dense white setae. Pronotum smooth, without wrinkles; epomia absent. Mesoscutum 1.11 times as long as wide. Notauli weakly impressed, nearly invisible near anterior margin of mesoscutum, extending back to level of tegulae. Mesopleuron smooth, without visible punctures, leather-like sculpture or wrinkles, with short but relatively dense hairs; speculum as remainder of mesopleuron. Epicnemial carina distinct, present ventrally and laterally. Metapleuron covered with very fine leather-like sculpture, without wrinkles. Submetapleural carina complete, expanded anteriorly into a lobe (the main part of this lobe belonging to metapleuron). Propodeum (Fig. 5) subpolished, smooth, without transverse wrinkles, crests or longitudinal groove.

Wings. Fore wing length $7.0 \mathrm{~mm}$. Marginal cell 0.25 times as long as wide; areolet present; distance between $2 r s-m$ and $2 m-c u 1.29$ times length of $2 r s-m ; M$ distinct; $c u-a$ inclivous, interstitial to Rs\&M. Hind wing length $5.2 \mathrm{~mm}$. All hind wing veins complete but $\mathrm{Cu} 1$ and $c u-a$ fine; first abscissa of $\mathrm{Cu} 1$ distinctly longer than $c u-a$ and joining $c u-a$ at a slight angle.

Legs. Hind femur (Fig. 6) 6.18 times as long as wide. Hind tibia with rather long but thin bristles. Lateral spur of hind tibia 0.55 times as long as first metatarsus (Fig. 7). Hind fifth tarsomere 0.65 times as long as third.

Metasoma. Tergites polished, with short, moderately dense pubescence, without distinct punctures. Tergite I (Figs 8-9) 1.91 times as long as posteriorly wide, with weak constriction between base and spiracle. Median basal pit of tergite I moderately deep; median dorsal carinae present along basal pit and finely raised. Dorsolateral edge of tergite I angled from base to apex. Tergite II 1.07 times as long as anteriorly wide and 0.75 times as long as posteriorly wide.

Colouration (Figs 1-9). Head predominantly black with following parts pale yellow: mandible (with exception of brown teeth), clypeus, maxillary and labial palps, malar space, central longitudinal stripe on face from base of clypeus to central part of face, spots on top of vertex, at eye margin. Antenna dark brown to black. Mesosoma predominantly dark orange with pale yellow/whitish and black marks; pale yellow/whitish: small marks on 
pronotum below tegula and above fore leg, tegula, marks on mesopleuron (small below tegula and large, irregular above mid coxa), anterolateral marks on mesoscutum, apex of scutellum, postscutellum, margins of axillary trough of mesonotum and metanotum; black: propleuron, broad band along anterior margin of pronotum, irregular mark on ventrolateral part of mesopleuron, axillary trough of metanotum (with exception of yellow margins) and mesonotum (along yellow margins), marks on mesoscutum (one near anterior margin and two, irregular on the sides of posterior part of mesoscutum), band along submetapleural carina, large irregular mark on propodeum. Fore and mid coxae, trochanters and trochantellus whitish, femora and tibiae yellow, trochanters and femora with black dorsal stripe, tarsi brownish. Hind leg: coxa whitish with black, irregular anterolateral mark, trochanter black, trochantellus pale yellow with black base, femur ventrally and partly laterally yellow, remainder black, tibia brownish, tarsomeres brownish with paler base. Wings hyaline, pterostigma yellowish brown, veins brown. First and following metasomal tergites black with narrow apical and lateral pale yellow bands (bands larger on the lateral part from third tergite to the apex of the abdomen). Ovipositor sheath blackish.

Male (GAULD et al. 1997) similar to female but with fore wing 4.5-5.0 mm and hind wing $3.1 \mathrm{~mm}$. Colour in general similar to female, but with yellow face and inner orbital stripe on frons, with only small orange mark on metapleuron and entirely black propodeum.

\section{Distribution}

Costa Rica (GAULD et al. 1997, CoRONADO-RIVERA 2009), Ecuador (new record).

\section{Biological notes}

Two males from Costa Rica were collected in a suburban garden at an altitude of 1300 $\mathrm{m}$ amsl in September-November (GAULD et al. 1997). In Ecuador, the female was collected in November in mountains around the town of Calacali, outside the nearby Geobotanical Reserve of Pululahua (Fig. 10), at an altitude above $3000 \mathrm{~m}$ amsl. There are no current host records.

\section{ACKNOWLEDGEMENTS}

We are extremely grateful to D. J. INCLÁN (Instituto Nacional del Biodiversidad (INB), Ecuador), who kindly provided ichneumonids collected in Ecuador, and to J. GRANADOS, who took the photo of the habitat of P. moragai in Ecuador. We express our thanks to G. BROAD (BMNH) for the type materials examined in this study. We would also like to thank two reviewers for their helpful comments on our manuscript. 


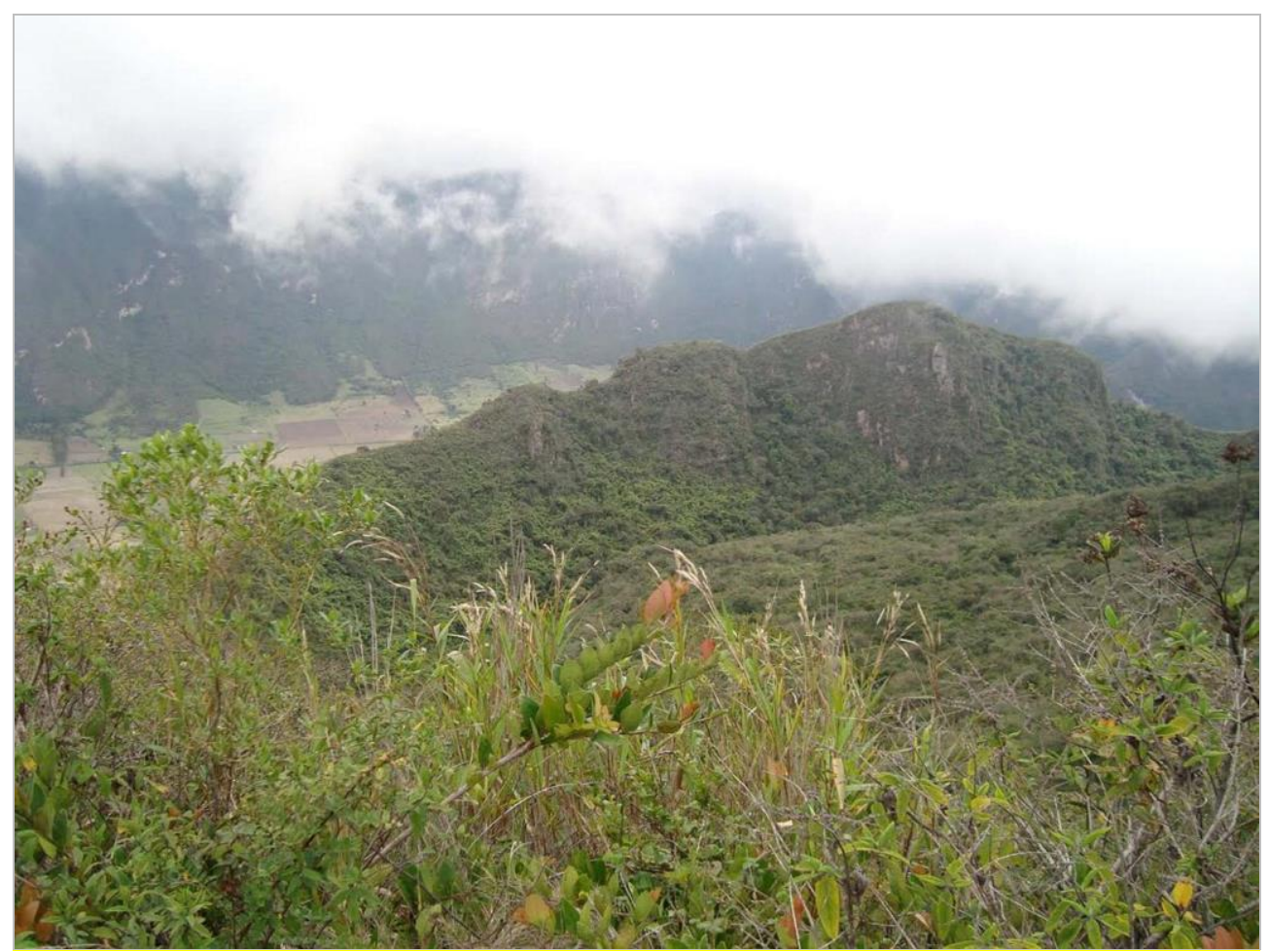

Fig. 10. Habitat of Phytodietus moragai in Ecuador.

\section{REFERENCES}

BenNetT A.M.R. 2015. Revision of the World Genera of Tryphoninae (Hymenoptera: Ichneumonidae). Memoirs of the American Entomological Institute 86: 1-387.

Coronado-Rivera J. 2009. Filogenia de avispas del género Netelia (Hymenoptera: Ichneumonidae) con énfasis en las especies costarricenses. Revista de Biologia Tropical 57(Suppl. 1): 213-238.

GAUld I., WAHL D., BradShaw K., HANSON P., WARD S. 1997. The Ichneumonidae of Costa Rica, 2. Introduction and keys to species of the smaller subfamilies, Anomaloninae, Ctenopelmatinae, Diplazontinae, Lycorininae, Phrudinae, Tryphoninae (excluding Netelia) and Xoridinae, with an appendix on the Rhyssinae. Memoirs of the American Entomological Institute 57: 1-485.

KaSPaRyan D.R. 2007. Review of Mexican species of the genus Phytodietus Gravenhorst (Hymenoptera: Ichneumonidae). Zoosystematica Rossica 16(1): 49-58.

Kasparyan D.R., Khalaim A.I. 2013. A new species of the genus Phytodietus Gravenhorst, 1829 (Hymenoptera: Ichneumonidae: Tryphoninae) from Mexico. Proceedings of the Zoological Institute of the Russian Academy of Sciences 317(1): 110-114.

Kasparyan D.R., Ruíz-Cancino E. 2004. Two new species of the genus Phytodietus Gravenhorst, 1829 (Hymenoptera: Ichneumonidae) from Mexico. Russian Entomological Journal 13: 73-76. 
Khalaim A.I., Ruíz-Cancino E., Coronado-Blanco J.M. 2013. New records of two rare species of the genus Phytodietus Gravenhorst, 1829 (Hymenoptera: Ichneumonidae: Tryphoninae) from Mexico. Russian Entomological Journal 22(2): 137-139.

Kostro-AmbroziaK A. 2011a. Phytodietus (Weisia) pearlus sp. nov. from South Africa (Hymenoptera: Ichneumonidae). Annales Zoologici 64(4): 803-805.

Kostro-Ambroziak A. 2011b. A new species of Phytodietus Gravenhorst, 1829 (Hymenoptera: Ichneumonidae: Tryphoninae) from North Africa. Entomological News 122(2): 149-153.

Kostro-Ambroziak A. 2012. Taxonomic study of the genus Phytodietus Gravenhorst, 1829 (Hymenoptera: Ichneumonidae) from Australia, with description of a new species. Deutsche Entomologische Zeitschrift 59(1): 139-145.

Kostro-Ambroziak A., Broad G. 2016. Genus Phytodietus Gravenhorst, 1829 new genus to South America, with description of a new species (Hymenoptera, Ichneumonidae, Tryphoninae). Annales Zoologici 66(1): 53-56.

Received: 9 November 2016

Accepted: 3 January 2017 